\title{
Uncontrolled hypertension in a child with Hurler syndrome
}

\author{
Christopher Eakins • J. Herman Kan
}

Received: 3 June 2010 /Revised: 9 July 2010 /Accepted: 13 July 2010/Published online: 13 August 2010

(C) Springer-Verlag 2010

A 15-year-old girl with Hurler syndrome was evaluated for recurrent hypertensive episodes with peak systolic pressures in excess of $175 \mathrm{mmHg}$. CT angiography demonstrates post-ductal long-segment aortic stenosis and beading of the descending aorta extending to the iliac bifurcation (Figs. 1 and 2).

Hurler syndrome is a mucopolysaccharidosis secondary to a deficit of lysosomal enzyme, alpha-L-iduronidase sulfate with characteristic skeletal, visceral, neurological and cardiovascular anomalies [1]. Hypertension has been described in Hurler syndrome in up to $32 \%$ of patients [2]. Mechanisms suggested are congenital or acquired architectural anomalies, atherosclerotic aortoiliac occlusive disease and

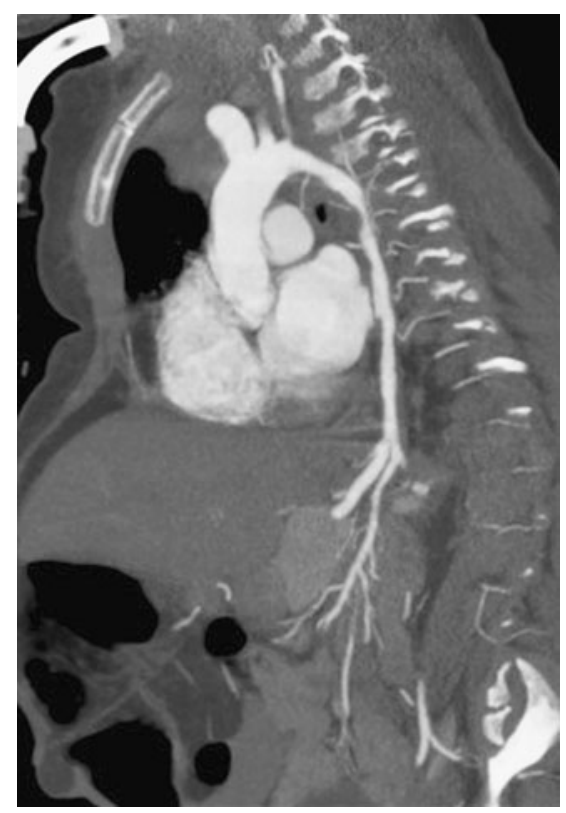

Fig. 1 Sagittal CTA

C. Eakins $(\bowtie) \cdot$ J. H. Kan

Department of Diagnostic Imaging,

Monroe Carell Jr. Children's Hospital at Vanderbilt,

2200 Children's Way, Suite 1421,

Nashville, TN 37232-9700, USA

e-mail: christopher.t.eakins@vanderbilt.edu

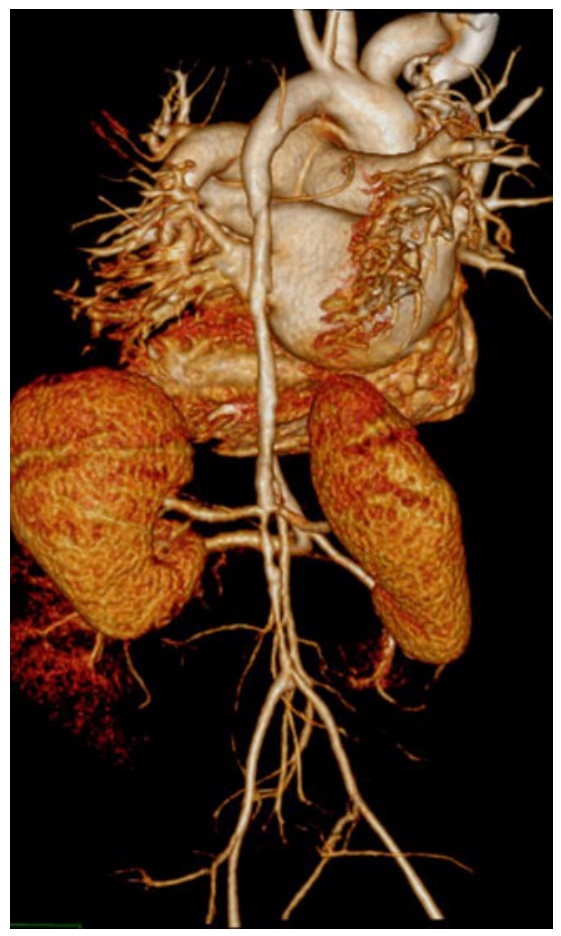

Fig. 2 Volume-rendered 3-D reformatted CTA

chronic upper airway obstruction [2]. Coarctation is a rare but described phenomenon in the presentation of Hurler syndrome [2]. Glycosaminoglycan accumulation in intimal cell and macrophage lysosomes leads to myointimal proliferation and aortic narrowing [1]. Although uncommon, aortic stenosis should be included in the differential diagnoses in children with Hurler syndrome and poorly controlled hypertension [2].

\section{References}

1. Braunlin EA, Krivit W, Burke BA et al (2000) Coarctation of the aorta in Hurler syndrome. Arch Pediatr Adolesc Med 154:841-842

2. Taylor DB, Blaser SI, Burrows PE et al (1991) Anteriopathy and coarctation of the abdominal aorta in children with mucopolysaccharidosis: imaging findings. AJR 157:819-823 